\title{
Impact of dental treatment on the oral health-related quality of life of Brazilian schoolchildren
}

\author{
Jordanna Guedes Amorim \\ MENDONÇA(a) $^{(\mathrm{D})}$ \\ Raquel Francis ALMEIDA(b) iD \\ Soraya Coelho LEAL $^{(b)}$ iD \\ Ítalo de Macedo BERNARDINO(c) \\ Leandro Augusto HILGERT(b) \\ Ana Paula Dias RIBEIRO(d) \\ (a) Universidade Federal de Goiás- UFG, \\ Department of Stomatologic Sciences, \\ Goiânia, GO, Brazil. \\ (b) Universidade de Brasília - UnB, School of \\ Health Sciences, Department of Dentistry, \\ Brasilia, DF, Brazil. \\ (c) Universidade Estadual da Paraíba - UEPB, \\ Department of Dentistry, Campina Grande, \\ PB, Brazil. \\ (d) University of Florida - UF, College of \\ Dentistry, Department of Restorative Dental \\ Sciences, Gainesville, FL, USA.
}

Declaration of Interests: The authors certify that they have no commercial or associative interest that represents a conflict of interest in connection with the manuscript.

Corresponding Author:

Ana Paula Dias Ribeiro

E-mail: aribeiro@dental.ufl.ed

ht1ps://doi.org/10.1590/1807-3107bor-2021.vol35.0125

Submitted: May 22, 2020

Accepted for publication: April 29, 2021

Last revision: May 20, 2021
Abstract: This before-after experimental study evaluated the impact of dental treatment on the oral health-related quality of life (OHRQoL) in children aged 6-8 years from Paranoá, DF, considering the presence or absence of cavitated dentin carious lesions pre- and post-treatment. The responsiveness and sensitivity of the questionnaires were also investigated. Caries was detected by using the Caries Assessment Spectrum and Treatment (CAST) instrument, while the impact of oral health on the children's health-related quality of life was assessed using the Brazilian version of the Child Perceptions Questionnaire $\left(\mathrm{CPQ}_{8-10}\right)$, which was completed by the children and the Brazilian version of the Early Childhood Oral Health Impact Scale (B-ECOHIS), which was completed by their parents. Sociodemographic characteristics were also assessed. After the examinations, the children were categorized into two groups according to the presence (treatment $/ \mathrm{n}=34$ ) or absence (control/n = 34) of cavitated dentin carious lesions. Restorative/curative care was provided to the treatment group, while the control group received preventive measures. OHRQoL was assessed at baseline and at four weeks post-treatment. No significant sociodemographic differences were observed between the groups. In the treatment group, the children and their families reported a greater impact of oral health on their OHRQoL in both questionnaires $(\mathrm{p}<0.05)$. However, there was a significant reduction in the impact of oral health, with differences between the pre-treatment and post-treatment phases $(p=0.001)$. Good sensitivity and responsiveness were observed for both questionnaires. Dental treatment was found to reduce the negative impact of dental caries on OHRQoL in 6-8-year-old children, which was detected by both questionnaires (B-ECOHIS and $\mathrm{CPQ}_{8-10}$ ).

Keywords: Quality of Life; Dental Caries; Child; Pain; Sensitivity and Specificity.

\section{Introduction}

Dental caries is one of the world's most common chronic childhood diseases and the fourth most expensive to treat. ${ }^{1}$ The first clinical manifestations of this multifactorial disease are asymptomatic visible alterations in the enamel, which can be treated through non-invasive and painless measures. ${ }^{2}$ However, parents often do not notice such signs in their children's teeth. Consequently, 
the lesions tend to progress to more advanced stages, which can lead to tooth loss. ${ }^{3}$ Epidemiological data have shown that most cavitated lesions in the dentin of primary teeth remain untreated, ${ }^{4}$ although dental treatment has proven to be an important strategy for minimizing or eliminating the consequences of untreated caries, which in more severe stages can negatively impact the daily life of children and their families. ${ }^{5}$

Therefore, there has been increasing interest in associating the quality of life data with the objective analysis of oral health, ${ }^{6}$ usually by determining the number of teeth affected by dental caries in both adults and children. With respect to children's oral health, ${ }^{7}$ several studies have shown a relationship between dental caries and lower quality of life in different age groups. ${ }^{8,70}$ Therefore, it is mandatory to assess the impact of dental treatment in reducing the negative effects of poor oral health status on children's quality of life.

Several versions of the oral health-related quality of life (OHRQoL) questionnaires have been developed to measure the functional and psychological impact of oral disorders on children under 8 years of age, based on information provided by the children or their caregivers about their daily lives. ${ }^{6-12}$ Many of these questionnaires have been tested for validity and reliability, but not for responsiveness and sensitivity, which are essential characteristics that demonstrate an instrument's ability to validly determine change over time. ${ }^{13-17}$ It should also be pointed out that none of these questionnaires have been validated for use in children aged 6 to 7 years.

Thus, the purposes of this study were to evaluate the impact of dental treatment on the OHRQoL of children with and without cavitated dentin carious lesions, by pre- and post-treatment intra- and intergroup analysis, and to test the responsiveness and sensitivity of the questionnaires applied. We hypothesized that the management of cavitated dentin lesions can reduce the negative impact of such conditions on the children's OHRQoL.

\section{Methodology}

\section{Ethical aspects}

This project was approved by the Ethics Committee of the Faculty of Health Sciences of the
University of Brasilia (CAAE registration number 51310415.0.0000.0030). An informed consent form was sent to the parents to explain the study and the voluntary nature of participation. Assent forms were also collected from the children.

\section{Study phases and sample selection}

This before-after experimental study was divided into two phases (Figure). Phase 1 occurred prior to dental treatment and included sending the consent form, a sociodemographic questionnaire, and the Brazilian version of the Early Childhood Oral Health ImpactScale (B-ECOHIS) questionnaire ${ }^{18}$ for the parents to answer; administering the Brazilian version of the Child Perceptions Questionnaire $\left(\mathrm{CPQ}_{8-10}\right)$ to the children (pre-treatment quality of life survey); and determining the children's oral health using the Caries Assessment Spectrum and Treatment (CAST) ${ }^{19}$ instrument. Phase 2 involved providing dental treatment to children with one or more cavitated dentin carious lesions (treatment group), preventive measures for those with none (control group), and re-applying the OHRQoL questionnaires to both parents and children 30 days post-treatment (post-treatment quality of life survey).

The inclusion criteria for Phase 1 were children aged 6 to 8 years enrolled in the second grade in the six public schools of Paranoá, DF. Paranoá is an administrative region of the Federal District, with a human development index of 0.785. According to official data, about $90 \%$ of the population are not covered by private health insurance, and less than $5 \%$ have a higher education level. Children who refused to be examined or parents who, due to some difficulty, were judged by their children being unable to answer the quality of life questionnaire, were excluded. In total, 374 children were included in this study.

For Phase 2, a sample size calculation was carried out based on the difference in toothache prevalence between the treatment and control groups. For a $40 \%$ difference, an alpha of 0.05 , a statistical power of $80 \%$, and 32 children randomly selected from among the six schools were required for each group.

Phase 1

The B-ECOHIS, ${ }^{18}$ sociodemographic questionnaire, and consent form were sent to the parents 


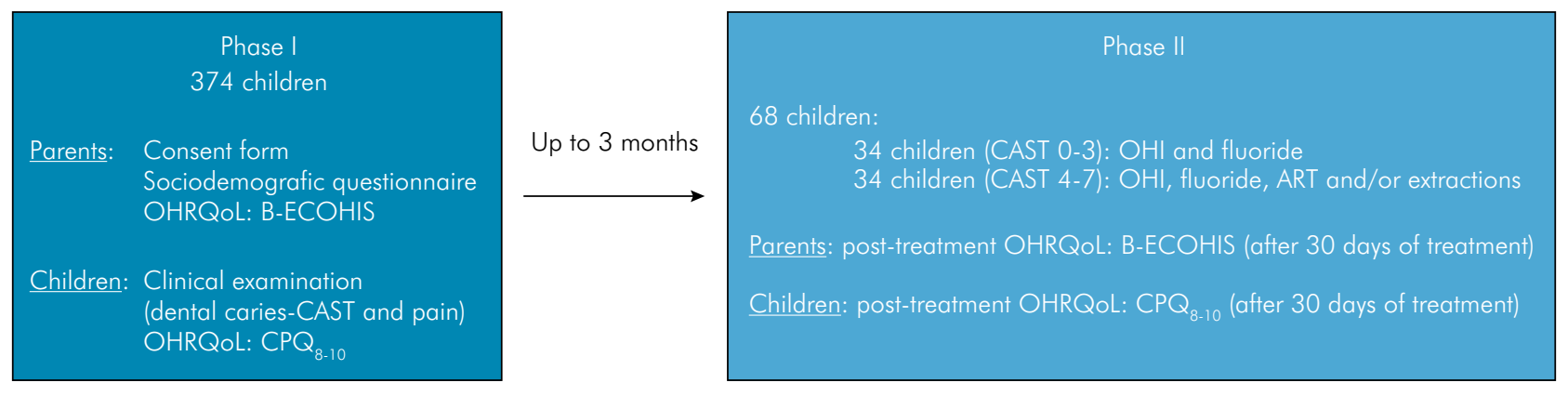

Figure. Flow chart for Phase I and Phase II, with sample size and evaluated variables.

(self-administered). The B-ECOHIS was completed by the parent or guardian, and it consisted of 13 items in two sections, the child impact section and the family impact section. These sections were divided into domains: four in the child impact section (symptom, function, psychological, and self-image/social interaction), and two in the family impact section (parent distress and family function). ${ }^{20}$ The sociodemographic questionnaire consisted of 21 questions covering the family's sociodemographic aspects and questions about the child's oral health.

The second step of this phase was a clinical examination of the participating children for toothache (reported by the child), and the assessment of dental caries using the $\mathrm{CAST}^{19}$ instrument. This instrument, which distinguishes all stages of dental caries, features 10 codes that assess dental caries from enamel carious lesions to tooth loss. ${ }^{14}$ Codes 1 and 2 refer to dental treatments; code 3 registers enamel carious lesions; codes 4 and 5 are related to dentin lesions without obvious cavitation and with cavitation, respectively; codes 6 and 7 are related to pulp exposure and fistula/ abscess; and code 8 indicates tooth loss due to dental caries. Moreover, the CAST instrument categorizes individuals in stages according to dental caries severity as follows: healthy (CAST codes 0,1 , and 2), pre-morbidity (CAST code 3 ), morbidity (CAST codes 4 and 5), severe morbidity (CAST codes 6 and 7), and mortality (CAST code 8).

Examinations of the 374 children were performed by two examiners under natural light supplemented with artificial light (a portable lamp). The equipment included a portable stretcher, clinical mirrors (Golgran, São Paulo, SP, Brazil), gauze (for tooth drying), and a WHO probe, which was used according to
WHO recommendations. ${ }^{21}$ The examiners had been previously trained and calibrated by an experienced epidemiologist, and the calibration procedures are described in detail elsewhere. ${ }^{22}$ The inter- and intra-examiner kappa values for the CAST instrument ranged from 0.89 to 0.93 . The prevalence rates of dentin carious lesions in these groups were $40.6 \%$ and $49.2 \%$, respectively, when including enamel lesions. Additionally,, the prevalence of dental pain was $2.8 \% .^{22}$

After the examination, the children's quality of life data were collected using the Brazilian version of the $\mathrm{CPQ}_{8-10}$ questionnaire, which was administered as an interview ${ }^{11}$ by trained personnel, which facilitated the comprehension of the questionnaire by the study population (6-8-year-old children). This questionnaire consisted of 29 questions on four subscales: oral symptoms, functional limitations, emotional well-being, and social well-being. It was applied in a separate setting from that of the clinical examination to avoid interference in the responses. ${ }^{16,23}$

\section{Phase 2}

The CAST codes were analyzed, and the children were divided into two groups: children presenting with CAST codes $0,1,2$, and 3 were considered healthy, while those with CAST codes 4, 5, 6, and 7 were considered to have a disease. Through a randomization process (randomize.org), the first 34 children without (CAST codes 0 to 3 ) and with caries (CAST codes 4 to 7 ), totaling 68 of the 374 children evaluated in phase 1 were then selected to comprise the control and treatment groups, respectively.

Treatments were carried out at the school premises. For CAST codes 4 and 5, that is carious 
lesions in the dentin that did not involve the pulp, painful symptoms and/or fistula were treated using the atraumatic restorative treatment. ${ }^{24}$ For CAST codes 6 and 7, the need for extraction was confirmed by radiography, which was performed at the school premises with a portable X-ray machine (70k periapical Rx, Dabi Atlante, Ribeirão Preto, Brazil). Extraction was performed only after obtaining the parents or guardians' consent at the school premises. There were also children who required endodontic treatment. These cases were referred to the pediatric dentistry clinic of the University Hospital of Brasilia due to the impossibility of performing such treatment under the provisory conditions at the school. Although both groups received oral health instructions and education on the application of fluoride varnish, this was the only treatment provided to the control group.

\section{Statistical analysis}

The collected data were analyzed using SPSS for Windows (version 20.0; SPSS Inc., Chicago, USA). Initially, descriptive statistics and proportions analysis (Pearson chi-square test or Fisher's exact test) were performed to assess the homogeneity of the groups (control vs. treatment) in relation to the sociodemographic characteristics. The normality of quantitative variables from the quality of life questionnaires was determined using the Shapiro-Wilk test. Non-parametric tests were used to determine the significance of differences within and between groups, regarding the questionnaire scores. The Wilcoxon signed-rank test (Phase 1 vs. Phase 2) and the Mann-Whitney U-test for independent groups (control vs. treatment) were also used.

The sensitivity of the B-ECOHIS and the Brazilian version of the $C P Q_{8-10}$ were assessed by determining changes in scores over time. ${ }^{14,15}$ Pre- and post-treatment scores were compared using the Wilcoxon signed-rank test. Effect size estimation indicated the magnitude of statistical variation. ${ }^{25}$ To test the change in responsiveness of both questionnaires, the standardized response mean (SRM) was computed ${ }^{26}$, with the values evaluated as follows: $\leq 0.2$, small effect; $0.3-0.7$, moderate effect; and $\geq 0.8$, large effect..$^{25}$ The minimally important difference (MID), which can be conceptualized as the smallest difference in score that the patients perceived as beneficial, was also estimated ${ }^{15}$. Internal consistency was analyzed using Cronbach's alpha.

\section{Results}

\section{Sample characterization and sociodemographic data}

In total, 68 children ( 34 in the treatment group and 34 in the control group) were included in this study. The majority were female (51.5\%), 7 years old $(76.5 \%)$, and those with mothers as head of the household (52.9\%). The parents or guardians generally had over 8 years of education (52.5\%), and $58.8 \%$ of this population had a monthly income varying between R \$678 and R\$1356 (US\$123.3 and US\$246.50).

In Phase 1, the sample was homogeneous in terms of sociodemographic and economic characteristics. Table 1 shows the characterization of the two groups.

\section{Assessment of the children's conditions in Phase 1 and Phase 2}

Table 2 shows the sample distribution regarding toothache, caries, and maximum CAST scores in Phases 1 and 2. In the treatment group, there was an expressive reduction in the prevalence of these conditions, with differences between the two phases.

\section{Evaluation of the quality of life questionnaires in Phase 1 and Phase 2}

The B-ECOHIS showed good internal consistency at baseline (Cronbach's alpha $=0.881$ ). Table 3 shows the total scores and scores for each B-ECOHIS domain in the different phases. There was a significant difference $(p<0.05)$ between the control and treatment groups in phase 1 . The perceived impact of oral health was significantly higher among the parents of children with CAST codes 5, 6, and 7. According to the B-ECOHIS scores, in phase 1 , the parents of children with cavitated dentin lesions reported a greater impact on the overall score $(p=0.001)$ and on the following domains: symptom $(p=0.001)$, function $(p=0.001)$, psychological $(p=0.001)$, self-image/social interaction $(p=0.010)$, parental distress $(p=0.001)$, and family function $(p=0.001)$. 
Table 1. Sample characterization according to the study groups (control and treatment).

\begin{tabular}{|c|c|c|c|c|}
\hline \multirow{2}{*}{ Variables } & Control group & Treatment group & \multicolumn{2}{|l|}{ Total } \\
\hline & n (\%) & n (\%) & $\mathrm{n}(\%)$ & $p$-value \\
\hline Sex & & & & $0.225^{a}$ \\
\hline Male & $14(41.2)$ & 19 (55.9) & $33(48.5)$ & \\
\hline Female & $20(58.8)$ & $15(44.1)$ & $35(51.5)$ & \\
\hline Age & & & & $0.332^{b}$ \\
\hline 6 years & $0(0.0)$ & $3(8.8)$ & $3(4.4)$ & \\
\hline 7 years & $28(82.4)$ & $24(70.6)$ & $52(76.5)$ & \\
\hline 8 years & $6(17.6)$ & 7 (20.6) & $13(19.1)$ & \\
\hline Lived with & & & & $0.783^{b}$ \\
\hline Father & $13(38.2)$ & $9(26.5)$ & $22(32.4)$ & \\
\hline Mother & $16(47.1)$ & $20(58.8)$ & $36(52.9)$ & \\
\hline Grandparent & $4(11.8)$ & $4(11.8)$ & 8 (11.8) & \\
\hline Other & $1(2.9)$ & $1(2.9)$ & $2(2.9)$ & \\
\hline Guardian's education & & & & $0.705^{a}$ \\
\hline$\leq 8$ years & $15(50.0)$ & $14(45.2)$ & $29(47.5)$ & \\
\hline$>8$ years & $15(50.0)$ & $17(54.8)$ & $32(52.5)$ & \\
\hline Monthly family income & & & & $1.000^{\circ}$ \\
\hline$<1 \times$ minimum monthly wage & $9(26.5)$ & $9(26.5)$ & $18(26.5)$ & \\
\hline $1-2 \times$ minimum monthly wage & $20(58.8)$ & $20(58.8)$ & $40(58.8)$ & \\
\hline$\geq 3 \times$ minimum monthly wage & $5(14.7)$ & $5(14.7)$ & $10(14.7)$ & \\
\hline \multicolumn{2}{|c|}{ Parent believes that the child needs dental treatment } & & & $0.053^{a}$ \\
\hline No & $5(14.7)$ & $0(0.0)$ & $5(7.5)$ & \\
\hline Yes & $29(85.3)$ & $33(100.0)$ & $62(92.5)$ & \\
\hline \multicolumn{2}{|c|}{ The child has been to the dentist at least once in his or her life } & & & $0.231^{\mathrm{a}}$ \\
\hline No & $14(41.2)$ & $9(27.3)$ & $23(34.3)$ & \\
\hline Yes & $20(58.8)$ & $24(72.7)$ & $44(65.7)$ & \\
\hline Toothache in the last three months & & & & $<0.001^{\mathrm{b}}$ \\
\hline No & $31(91.2)$ & $14(41.2)$ & $45(66.2)$ & \\
\hline Yes & $3(8.8)$ & $20(58.8)$ & $23(33.8)$ & \\
\hline
\end{tabular}

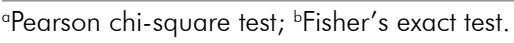

Significant intragroup differences $(p<0.001)$ were observed in the treatment group between phase 1 and phase 2. The mean total pre-treatment B-ECOHIS score was $14.94 \pm 8.84$ in Phase 1 (pre-treatment) and $1.41 \pm 1.83$ in phase 2 (post-treatment), with approximately $90 \%$ reduction in total score. There was a significant difference in the reduction of the mean and median total B-ECOHIS scores between Phase 1 and Phase 2 ( $p<0.001)$, indicating that, according to their parents, the children's OHRQoL improved. For each B-ECOHIS domain, the mean and median baseline values were significantly higher than those found in Phase 2 ( $p<0.001$ ), indicating an improvement in all aspects of oral health post-treatment (Table 3).
The Brazilian version of the $\mathrm{CPQ}_{8-10}$ also showed good internal consistency in Phase 1 (Cronbach's alpha $=0.890$ ). Table 4 shows the total and individual subscale scores for the $\mathrm{CPQ}_{8-10}$ in Phase 1 and Phase 2 . There was a statistically significant difference $(p<0.05)$ between the control and treatment groups in phase 1 . The perceived impact of oral health on the children's quality of life was significantly higher in the treatment group according to the $\mathrm{CPQ}_{8-10}$ scores. In Phase 1, this group reported a greater impact on the overall score $(p=0.004)$ and on the following subscales: oral symptoms $(p=0.005)$, emotional well-being $(p=0.004)$, and social well-being $(p=0.004)$. In Phase 2, this group reported a greater impact on the 
Table 2. Distribution of children according to the occurrence of toothache, dentin caries and maximum CAST score at Phase 1 and Phase 2.

\begin{tabular}{|c|c|c|c|}
\hline \multirow{2}{*}{ Variables } & Control group & Treatment group & Total \\
\hline & $\mathrm{n}(\%)$ & n (\%) & n (\%) \\
\hline \multicolumn{4}{|l|}{ Toothache (phase 1) } \\
\hline Absent & $31(91.2)$ & $24(70.6)$ & $55(80.9)$ \\
\hline Present & $3(8.8)$ & $10(29.4)$ & $13(19.1)$ \\
\hline \multicolumn{4}{|l|}{ Toothache (phase 2) } \\
\hline Absent & $32(94.1)$ & $33(97.1)$ & $65(95.6)$ \\
\hline Present & $2(5.9)$ & $1(2.9)$ & $3(4.4)$ \\
\hline \multicolumn{4}{|l|}{ Dentin caries (phase 1) } \\
\hline Absent & $34(100)$ & $0(0.0)$ & $34(50)$ \\
\hline Present & $0(0.0)$ & $34(100)$ & $34(50)$ \\
\hline \multicolumn{4}{|l|}{ Dentin caries (phase 2) } \\
\hline Absent & $34(100.0)$ & $34(100)$ & $68(100)$ \\
\hline Present & $0(0.0)$ & $0(00.0)$ & $0(0.0)$ \\
\hline \multicolumn{4}{|l|}{ Maximum CAST score (phase 1) } \\
\hline Healthy & $28(82.4)$ & $0(0.0)$ & $28(41.2)$ \\
\hline Restauration & $2(5.9)$ & $0(0.0)$ & $2(2.9)$ \\
\hline Enamel & $4(11.8)$ & $0(0.0)$ & $4(5.9)$ \\
\hline Dentin (clear cavitation in the dentin) & $0(0.0)$ & $4(11.8)$ & $4(5.9)$ \\
\hline Pulp & $0(0.0)$ & $13(38.2)$ & $13(19.1)$ \\
\hline Abscess/fistula & $0(0.0)$ & $1(2.9)$ & $1(1.5)$ \\
\hline Lost & $0(0.0)$ & $16(47)$ & $16(23.6)$ \\
\hline \multicolumn{4}{|l|}{ Maximum CAST score (phase 2) } \\
\hline Healthy & $28(82.4)$ & $0(0.0)$ & $28(41.2)$ \\
\hline Restauration & $2(5.9)$ & $5(14.7)$ & 7 (10.3) \\
\hline Enamel & 4 (1 1.8) & $0(0.0)$ & $4(5.9)$ \\
\hline Lost & $0(0.0)$ & $29(85.3)$ & $29(42.6)$ \\
\hline
\end{tabular}

overall score $(p=0.016)$ and on functional limitations subscale $(\mathrm{p}=0.001)$.

Significant intragroup differences $(p<0.001)$ were also observed in the treatment group between phase 1 and phase 2. The mean total $\mathrm{CPQ}_{8-10}$ score was $20.79 \pm 14.92$ in Phase 1 and $5.35 \pm 7.98$ in Phase 2 , with a reduction of approximately $74 \%$. $(\mathrm{p}<0.001)$, indicating an improvement in their OHRQoL. For each $\mathrm{CPQ}_{8-10}$ subscale, the mean/median Phase 1 values were also significantly higher than the Phase 2 values $(\mathrm{p}<0.001)$, indicating post-treatment improvement in all aspects of oral health (Table 4 ).

\section{Questionnaire sensitivity and responsiveness}

The change in the mean total B-ECOHIS score for the treatment group was $13.53 \pm 8.05$, which was calculated by subtracting the baseline scores from the follow-up scores. A positive change indicated an improved OHRQoL. The highest mean change among the subscales was observed in the functional domain $(3.76 \pm 3.34)$. In addition, there was a large effect size for the magnitude of change in total B-ECOHIS score (1.53), as well as for the symptom (1.65), function (1.10), psychological (1.11), parent distress (1.61), and family function domains (0.89). A moderate effect size was found in the self-image/social interaction domain (0.74) (Table 5). The SRM values were high for total B-ECOHIS score (1.68), as well as for the symptoms (1.64), function (1.13), psychological (1.18), parent distress (1.64), and family function domains (0.92). A moderate SRM value was observed in the self-image/social interaction domain (0.75). The MID for the total B-ECOHIS score was 0.92 , whereas among the six subscales, the parent distress domain had the 
Table 3. Measures of central tendency and variability in B-ECOHIS and subscale scores according to group and point in time [control and treatment groups in Phases 1 and 2].

\begin{tabular}{|c|c|c|c|c|c|c|}
\hline \multirow{3}{*}{ Variable } & \multicolumn{6}{|c|}{ Point in time } \\
\hline & \multicolumn{3}{|c|}{ Phase 1} & \multicolumn{3}{|c|}{ Phase 2} \\
\hline & Mean (SD) & Median & IQR & Mean (SD) & Median & $I Q R$ \\
\hline \multicolumn{7}{|l|}{ Control group } \\
\hline \multicolumn{7}{|l|}{ B-ECOHIS } \\
\hline Overall score & $4.35(5.01)$ & 2.00 & $1.50-6.25$ & $2.18(2.62)$ & 1.50 & $0.00-3.25$ \\
\hline \multicolumn{7}{|l|}{ Child Section (subscale) } \\
\hline 1. Symptom domain & $0.59(0.96)$ & 0.00 & $0.00-1.00$ & $0.29(0.63)^{b}$ & 0.00 & $0.00-0.00$ \\
\hline 2. Function domain & $1.35(1.67)$ & 0.50 & $0.00-2.25$ & $0.94(1.58)^{\mathrm{b}}$ & 0.00 & $0.00-2.00$ \\
\hline 3. Psychological domain & $0.44(0.99)$ & 0.00 & $0.00-0.00$ & $0.18(0.76)$ & 0.00 & $0.00-0.00$ \\
\hline 4. Self-image/social interaction domain & $0.38(0.89)$ & 0.00 & $0.00-0.00$ & $0.12(0.48)$ & 0.00 & $0.00-0.00$ \\
\hline \multicolumn{7}{|l|}{ Family Section (subscale) } \\
\hline 5. Parent distress domain & $1.03(1.88)$ & 0.00 & $0.00-2.00$ & $0.41(1.08)$ & 0.00 & $0.00-0.00$ \\
\hline 6. Family function domain & $0.56(1.50)$ & 0.00 & $0.00-0.25$ & $0.24(0.61)$ & 0.00 & $0.00-0.00$ \\
\hline \multicolumn{7}{|l|}{ Treatment group } \\
\hline \multicolumn{7}{|l|}{ B-ECOHIS } \\
\hline Overall score & $14.94(8.84)^{a}$ & 14.00 & $6.75-21.25$ & $1.41(1.83)^{c}$ & 1.00 & $0.00-2.00$ \\
\hline \multicolumn{7}{|l|}{ Child section (subscale) } \\
\hline 1. Symptom domain & $1.85(1.10)^{a}$ & 2.00 & $1.00-2.00$ & $0.03(0.17)^{c}$ & 0.00 & $0.00-0.00$ \\
\hline 2. Function domain & $3.94(3.41)^{a}$ & 3.50 & $1.50-6.25$ & $0.18(0.58)^{c}$ & 0.00 & $0.00-0.00$ \\
\hline 3. Psychological domain & $2.26(1.85)^{a}$ & 2.00 & $0.00-4.00$ & $0.21(0.54)^{c}$ & 0.00 & $0.00-0.00$ \\
\hline 4. Self-image/social interaction domain & $1.32(1.74)^{a}$ & 0.00 & $0.00-2.00$ & $0.03(0.17)^{c}$ & 0.00 & $0.00-0.00$ \\
\hline \multicolumn{7}{|l|}{ Family section (subscale) } \\
\hline 5. Parent distress domain & $3.82(1.88)^{a}$ & 4.00 & $2.00-5.00$ & $0.79(1.37)^{c}$ & 0.00 & $0.00-1.00$ \\
\hline 6. Family function domain & $1.74(1.76)^{\mathrm{a}}$ & 2.00 & $0.00-2.25$ & $0.18(0.63)^{c}$ & 0.00 & $0.00-0.00$ \\
\hline
\end{tabular}

SD: standard deviation; IQR: interquartile range $\left(25^{\text {th }}-75^{\text {th }}\right.$ percentile). ${ }^{a}$ Significant difference between control and treatment groups at phase

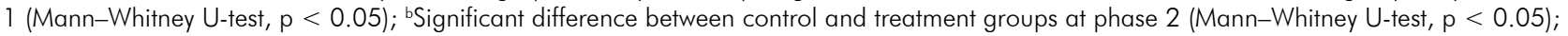
cSignificant difference between Phase 1 and Phase 2 in the treatment group (Wilcoxon signed-rank test, $p<0.001$ ); ${ }^{*}$ No significant difference was found between Phase 1 and Phase 2 in the control group (Wilcoxon signed-rank test, $p>0.001$ ).

highest value (0.69). All these values were lower than the change in mean score (Table 5).

Table 6 shows the sensitivity and responsiveness of the $\mathrm{CPQ}_{8-10}$ to treatment. The mean total change in the $\mathrm{CPQ}_{8-10}$ score was $15.44 \pm 13.28$ for the treatment group. The greatest mean change for any subscale was observed in oral symptoms $(4.65 \pm 4.14)$. In addition, there was a large effect size for the magnitude of change in the total $\mathrm{CPQ}_{8-10}$ score (1.03), as well as for the oral symptoms (1.11), functional limitations (0.91), and well-being subscales $(0.85)$. There was a moderate effect size for the social well-being subscale (0.65). $\mathrm{SRM}$ values were high for the total $\mathrm{CPQ}_{8-10}$ score (1.16), as well as for oral symptoms (1.12), functional limitations (1.10), and emotional well-being subscales (0.83). There was a moderate value for the social well-being subscale (0.76). The MID for total $\mathrm{CPQ}_{8-10}$ score was 3.99. Of the four subscales, the highest MID value was observed in the emotional well-being subscale (1.47). All these values were lower than the change in mean scores (Table 6).

\section{Discussion}

The results of this investigation showed a clear and positive impact of dental treatment on the OHRQoL of children aged 6-8 years, who were affected by untreated dental caries at the cavitation level. Their OHRQoL improved significantly after treatment, which was perceived not only by the child, but also by a family member. The scores of both questionnaires, $\mathrm{CPQ}_{8-10}$ and $\mathrm{B}-\mathrm{ECOHIS}$, reduced 
Impact of dental treatment on the oral health-related quality of life of Brazilian schoolchildren

Table 4. Measures of central tendency and variability in $C P Q_{8-10}$ and subscale scores according to group and point in time [control and treatment groups in Phases 1 and 2].

\begin{tabular}{|c|c|c|c|c|c|c|}
\hline \multirow{3}{*}{ Variable } & \multicolumn{6}{|c|}{ Point in time } \\
\hline & \multicolumn{3}{|c|}{ Phase 1} & \multicolumn{3}{|c|}{ Phase 2} \\
\hline & Mean (SD) & Median & IQR & Mean (SD) & Median & IQR \\
\hline \multicolumn{7}{|l|}{ Control group } \\
\hline \multicolumn{7}{|l|}{$C P Q_{8-10}$} \\
\hline Overall score & $12.21(12.83)$ & 7.50 & 2.00-19.00 & $8.85(8.75)^{b}$ & 6.00 & $3.75-12.25$ \\
\hline \multicolumn{7}{|l|}{ Subscale } \\
\hline 1. Oral symptoms & $4.00(3.73)$ & 2.50 & $1.75-6.00$ & $2.94(2.95)$ & 2.00 & $0.75-4.25$ \\
\hline 2. Functional limitations & $3.21(3.92)$ & 2.00 & $0.00-5.25$ & $2.88(2.77)^{\mathrm{b}}$ & 2.00 & $0.00-4.00$ \\
\hline 3. Emotional well-being & 2.29 (3.23) & 1.00 & $0.00-2.50$ & $1.74(3.02)$ & 0.00 & $0.00-2.00$ \\
\hline 4. Social well-being & $2.71(4.15)$ & 0.50 & $0.00-4.00$ & $1.29(2.11)$ & 0.00 & $0.00-2.00$ \\
\hline \multicolumn{7}{|l|}{ Treatment group } \\
\hline \multicolumn{7}{|l|}{$C P Q_{8-10}$} \\
\hline Overall score & $20.79(14.92 a$ & 16.50 & $9.00-32.50$ & $5.35(7.98)^{c}$ & 2.00 & $0.75-7.00$ \\
\hline \multicolumn{7}{|l|}{ Subscale } \\
\hline 1. Oral symptoms & $6.68(4.18)^{a}$ & 6.00 & $4.00-9.00$ & $2.03(2.67)^{c}$ & 2.00 & $0.00-2.00$ \\
\hline 2. Functional limitations & $4.44(3.66)$ & 4.00 & $1.00-6.50$ & $1.12(2.28)^{c}$ & 0.00 & $0.00-2.00$ \\
\hline 3. Emotional well-being & $4.94(4.40)^{a}$ & 4.00 & $1.00-9.00$ & $1.21(2.93)^{c}$ & 0.00 & $0.00-1.00$ \\
\hline 4. Social well-being & $4.74(5.76)^{a}$ & 3.00 & $0.75-6.50$ & $1.00(1.86)^{c}$ & 0.00 & $0.00-2.00$ \\
\hline
\end{tabular}

SD: standard deviation; IQR: interquartile range $\left(25^{\text {th }}-75^{\text {th }}\right.$ percentile). ${ }^{a}$ Significant difference between control and treatment groups at phase 1 (Mann-Whitney U-test, $\mathrm{p}<0.05$ ); bSignificant difference between control and treatment groups in phase 2 (Mann-Whitney U-test, $p<0.05$ ); 'Significant difference between Phase 1 and Phase 2 surveys in the treatment group (Wilcoxon signed-rank test, $p<0.001$ ); *No significant difference was found between Phase 1 and Phase 2 for the control group (Wilcoxon signed-rank test, $p>0.001$ ).

Table 5. Sensitivity and responsiveness of the B-ECOHIS to caries treatment.

\begin{tabular}{|c|c|c|c|c|}
\hline Group & Mean score change (SD) & Cohen's d ${ }^{a}$ & $\mathrm{SRM}^{\mathrm{b}}$ & MID \\
\hline \multicolumn{5}{|l|}{ Control group } \\
\hline \multicolumn{5}{|l|}{ B-ECOHIS } \\
\hline Overall score & $2.18(5.09)$ & 0.44 & 0.43 & - \\
\hline \multicolumn{5}{|l|}{ Child section (subscale) } \\
\hline 1. Symptom domain & $0.29(0.84)$ & 0.30 & 0.35 & - \\
\hline 2. Function domain & $0.41(1.23)$ & 0.25 & 0.33 & - \\
\hline 3. Psychological domain & $0.26(0.86)$ & 0.26 & 0.30 & - \\
\hline 4. Self-image/social interaction domain & $0.26(0.79)$ & 0.29 & 0.33 & - \\
\hline \multicolumn{5}{|l|}{ Family section (subscale) } \\
\hline 5. Parent distress domain & $0.62(1.88)$ & 0.33 & 0.33 & - \\
\hline 6. Family function domain & $0.32(1.59)$ & 0.21 & 0.20 & - \\
\hline \multicolumn{5}{|l|}{ Treatment group } \\
\hline \multicolumn{5}{|l|}{ B-ECOHIS } \\
\hline Overall score & $13.53(8.05)$ & 1.53 & 1.68 & 0.92 \\
\hline \multicolumn{5}{|l|}{ Child section (subscale) } \\
\hline 1. Symptom domain & $1.82(1.11)$ & 1.65 & 1.64 & 0.09 \\
\hline 2. Function domain & $3.76(3.34)$ & 1.10 & 1.13 & 0.29 \\
\hline 3. Psychological domain & $2.06(1.74)$ & 1.11 & 1.18 & 0.27 \\
\hline 4. Self-image/social interaction domain & $1.29(1.73)$ & 0.74 & 0.75 & 0.09 \\
\hline \multicolumn{5}{|l|}{ Family section (subscale) } \\
\hline 5. Parent distress domain & $3.03(1.85)$ & 1.61 & 1.64 & 0.69 \\
\hline 6. Family function domain & $1.56(1.69)$ & 0.89 & 0.92 & 0.32 \\
\hline
\end{tabular}

SD: standard deviation; ${ }^{\circ}$ effect size; ${ }^{b S R M}$ : standardized response mean; ${ }^{c} M I D$ : minimally important difference. 
Table 6. Sensitivity and responsiveness of the $C P Q_{8-10}$ to caries treatment.

\begin{tabular}{|c|c|c|c|c|}
\hline Group & Mean score change (SD) & Cohen's d ${ }^{a}$ & $\mathrm{SRM}^{\mathrm{b}}$ & $\mathrm{MID}^{\mathrm{c}}$ \\
\hline \multicolumn{5}{|l|}{ Control group } \\
\hline \multicolumn{5}{|l|}{$C P Q_{8-10}$} \\
\hline Overall score & $3.35(8.76)$ & 0.26 & 0.38 & - \\
\hline \multicolumn{5}{|l|}{ Subscale } \\
\hline 1. Oral symptoms & $1.06(3.14)$ & 0.28 & 0.34 & - \\
\hline 2. Functional limitations & $0.32(2.17)$ & 0.08 & 0.15 & - \\
\hline 3. Emotional well-being & $0.56(2.36)$ & 0.17 & 0.24 & - \\
\hline 4. Social well-being & $1.41(4.36)$ & 0.34 & 0.32 & - \\
\hline \multicolumn{5}{|l|}{ Treatment group } \\
\hline \multicolumn{5}{|l|}{$C P Q_{8-10}$} \\
\hline Overall score & $15.44(13.28)$ & 1.03 & 1.16 & 3.99 \\
\hline \multicolumn{5}{|l|}{ Subscale } \\
\hline 1. Oral symptoms & $4.65(4.14)$ & 1.11 & 1.12 & 1.34 \\
\hline 2. Functional limitations & $3.32(3.03)$ & 0.91 & 1.10 & 1.14 \\
\hline 3. Emotional well-being & $3.74(4.53)$ & 0.85 & 0.83 & 1.47 \\
\hline 4. Social well-being & $3.74(4.94)$ & 0.65 & 0.76 & 0.93 \\
\hline
\end{tabular}

SD: standard deviation; ${ }^{a}$ effect size; ${ }^{b}$ SRM: standardized response mean; ${ }^{c M I D}$ : minimally important difference.

dramatically from phase 1 to phase 2 . Moreover, the domains and subscales of each questionnaire reflected these reductions.

This age group (6 to 8 years old) was selected due to the lack of published studies on this topic among children in this age group. ${ }^{8,27}$ The gap in the literature can be explained by the absence of a specific instrument to assess children's perception of OHRQoL in this age group ${ }^{8}$ based on concerns that children under 8 years of age could not satisfactorily respond to questions because of their communication and cognitive limitations. However, it has been demonstrated that children already have the capacity to self-evaluate, form abstract thoughts, and make judgments at 6 years of age. ${ }^{28}$ In addition, the interview format applied by the trained personnel in a quiet environment allowed a better comprehension of the questions by the study population. Our results showed that the perception of the children and that of their parents matched, with respect to the children's OHRQoL, which allowed us to infer that the children were able to correctly express their feelings.

In addition, evaluating parental perceptions is important, since a child's dental problem can lead to lost sleep and workdays, cause additional expenses, and feelings of guilt in the parents., ${ }^{5,29}$
Martins-Junior et al. ${ }^{10}$ showed the effectiveness of the B-ECOHIS in assessing the impact of early childhood caries (ECC) on the OHRQoL of preschool children and their families. In our study, the parents' scores for guilt and distress in the B-ECOHIS "family section" remained higher in the treatment group than in the control group, even after treatment, indicating that despite improved oral health, some OHRQoL aspects are difficult to change. In a recent study, ${ }^{30}$ parents feeling upset and guilt were the most frequently reported domains at baseline, and even after treatment, some parents still felt guilty. The authors believe that families with better financial conditions that did not use preventive therapy or treatment at the initial stages felt more anguished. Therefore, improving parents' knowledge of oral health in order to seek early treatment and prioritize preventive care rather than treatment is of utmost importance. ${ }^{29}$

The effect size (ES) and standardized response mean (SRM) for both questionnaires were considered large when comparing Phase 1 (before treatment) and Phase 2 (post-treatment) in the treatment group. A similar overall score for B-ECOHIS and effect size was reported by Vollú et al..$^{30}$ when evaluating the OHRQoL 30 days after dental treatment in 16 preschool children with ECC. Abanto et al. ${ }^{31}$ 
also confirmed that dental treatment improved the OHRQoL in children aged 3-5 years, with both ES and SRM considered large. On the other hand, only subtle changes were observed in the control group, as was the case in previous studies. ${ }^{24,32}$ This reinforces the concept that dental caries at the morbidity and severe morbidity stages negatively impact OHRQoL. It also demonstrates that the improvement of OHRQoL depends significantly on oral health prior to treatment. ${ }^{33}$

Our results also showed that the presence of cavitated carious lesions significantly increased the total B-EOCHIS and $\mathrm{CPQ}_{8-10}$ scores, that is untreated caries negatively impacted children's quality of life. This impact is more clearly perceived at more severe stages of the disease, such as caries involving the pulp, fistulas, abscesses, pain, or residual roots. ${ }^{8}$ Therefore, the use of caries detection instruments, such as CAST, ${ }^{19}$ in which dentin carious lesions are registered at different levels-shadow in dentin without an obvious cavitation, cavitation, pulp exposure, and fistula/abscess-are recommended. Based on the stratification of individuals by CAST codes into healthy, pre-morbidity, severe morbidity, and mortality stages, one can speculate about the impact of oral health/dental treatment on a child's quality of life. Vollú et al. ${ }^{30}$ observed that children who underwent extractions or required a space maintainer during the treatment phase presented higher B-ECOHIS scores than those who did not experience any of those treatment options. If children at an early age already have problems concerning their OHRQoL, we should really consider the promotion of oral health through educational programs, to control this preventable disease. ${ }^{8}$

Regarding the characterization of our sample, the socio-demographic characteristics of both groups were similar, consisting mostly of low-income families. Such findings were expected, since the region in which the study was carried out is one of the poorest areas of Brazil's Federal District. ${ }^{34}$ Although there were healthy children identified by the CAST instrument who were enrolled in the control group, the children in the treatment group presented with precarious oral health conditions that can be, in part, explained by the social vulnerability of the families. The literature shows that children from families whose income is no more than two times the minimum monthly wage are more likely to have oral problems and, consequently, poorer OHRQoL. ${ }^{35,36,37}$

Our study also tested the sensitivity and responsiveness of the B-ECOHIS and $\mathrm{CPQ}_{8-10}$, and the results were satisfactory. Measures of effect size and mean score difference demonstrated that the instruments were valid for evaluating changes in the quality of life of children aged 6 to 8 years after dental treatment. This means that such questionnaires can be used in future clinical trials involving children in this age group. We also tested the internal consistency of the instruments, and in both cases, the Cronbach's alpha coefficient values were close to 1 , indicating good consistency.

Our results provide original evidence for the impact of dental treatment on the OHRQoL of schoolchildren aged 6 to 8 years, and the validity of using both $\mathrm{CPQ}_{8-10}$ and B-ECOHIS as instruments to assess this impact. The limitations of our study include the short-term evaluation (only 30 days) and the use of $C P Q_{8-10}$ in a different age population. The $\mathrm{CPQ}_{8-10}$ was applied in an interview format to allow a better comprehension in the children, changing its original concept (self-application). In addition, no previous test was performed on the children to evaluate their understanding. Longer evaluation periods should be included in future studies to evaluate the long-term effects on their OHRQoL and on their families.

\section{Conclusions}

It can be concluded that cavitated dentin carious lesions worsened the OHRQoL of 6-8 years old children, and this impact can be overcome by dental treatment. Moreover, $\mathrm{CPQ}_{8-10}$ and B-ECOHIS can be used as safe tools to evaluate OHRQoL in this age population.

\section{Acknowledgements}

This study received a research grant from the Brazilian Federal District Research Support Foundation (FAPDF). 


\section{References}

1. Arora A, Scott JA, Bhole S, Do L, Schwarz E, Blinkhorn AS. Early childhood feeding practices and dental caries in preschool children: a multi-centre birth cohort study. BMC Public Health. 2011 Jan;11(1):28. https://doi.org/10.1186/1471-2458-11-28

2. Holmgren C, Gaucher C, Decerle N, Doméjean S. Minimal intervention dentistry II: part 3. Management of non-cavitated (initial) occlusal caries lesions-non-invasive approaches through remineralisation and therapeutic sealants. Br Dent J.

2014 Mar;216(5):237-43. https://doi.org/10.1038/sj.bdj.2014.147

3. Kosmala-Anderson J, Wallace LM. Breastfeeding works: the role of employers in supporting women who wish to breastfeed and work in four organizations in England. J Public Health (Oxf). 2006 Sep;28(3):183-91. https://doi.org/10.1093/pubmed/fdl012

4. Mota-Veloso I, Soares ME, Alencar BM, Marques LS, Ramos-Jorge ML, Ramos-Jorge J. Impact of untreated dental caries and its clinical consequences on the oral health-related quality of life of schoolchildren aged 8-10 years. Qual Life Res. 2016 Jan;25(1):193-9. https://doi.org/10.1007/s11136-015-1059-7

5. Klaassen MA, Veerkamp JS, Hoogstraten J. Young children's oral health-related quality of life and dental fear after treatment under general anaesthesia: a randomized controlled trial. Eur J Oral Sci. 2009 Jun;117(3):273-8. https://doi.org/10.1111/j.1600-0722.2009.00627.x

6. Alsumait A, EISalhy M, Raine K, Cor K, Gokiert R, Al-Mutawa S, et al. Impact of dental health on children's oral health-related quality of life: a cross-sectional study. Health Qual Life Outcomes. 2015 Jul;13(1):98. https://doi.org/10.1186/s12955-015-0283-8

7. Gomes MC, Pinto-Sarmento TC, Costa EM, Martins CC, Granville-Garcia AF, Paiva SM. Impact of oral health conditions on the quality of life of preschool children and their families: a cross-sectional study. Health Qual Life Outcomes. 2014 Apr;12(1):55. https://doi.org/10.1186/1477-7525-12-55

8. Leal SC, Bronkhorst EM, Fan M, Frencken JE. Untreated cavitated dentine lesions: impact on children's quality of life. Caries Res. 2012;46(2):102-6. https://doi.org/10.1159/000336387

9. Kramer PF, Feldens CA, Ferreira SH, Bervian J, Rodrigues PH, Peres MA. Exploring the impact of oral diseases and disorders on quality of life of preschool children. Community Dent Oral Epidemiol. 2013 Aug;41(4):327-35. https://doi.org/10.1111/cdoe.12035

10. Martins-Júnior PA, Oliveira M, Marques LS, Ramos-Jorge ML. Untreated dental caries: impact on quality of life of children of low socioeconomic status. Pediatr Dent. 2012 May-Jun;34(3):49-52.

11. Jokovic A, Locker D, Stephens M, Kenny D, Tompson B, Guyatt G. Validity and reliability of a questionnaire for measuring child oral-health-related quality of life. J Dent Res. 2002 Jul;81(7):459-63. https://doi.org/10.1177/154405910208100705

12. Martins MT, Sardenberg F, Bendo CB, Vale MP, Paiva SM, Pordeus IA. Dental caries are more likely to impact on children's quality of life than malocclusion or traumatic dental injuries. Eur J Paediatr Dent. 2018 Sep;19(3):194-8.

13. Locker D, Jokovic A, Clarke M. Assessing the responsiveness of measures of oral health-related quality of life. Community Dent Oral Epidemiol. 2004 Feb;32(1):10-8. https://doi.org/10.1111/j.1600-0528.2004.00114.x

14. Lee GH, McGrath C, Yiu CK, King NM. Sensitivity and responsiveness of the Chinese ECOHIS to dental treatment under general anaesthesia. Community Dent Oral Epidemiol. 2011 Aug;39(4):372-7. https://doi.org/10.1111/j.1600-0528.2010.00604.x

15. Martins-Júnior PA, Almeida L, Silva VS, Paiva SM, Marques LS, Ramos-Jorge ML. Sensitivity and responsiveness to change for the Brazilian version of the child perceptions questionnaire for 8 - to 10-year-old children. J Public Health. 2018;26(1):15-21. https://doi.org/10.1007/s10389-017-0848-6

16. Barbosa TS, Tureli MC, Gavião MB. Validity and reliability of the Child Perceptions Questionnaires applied in Brazilian children. BMC Oral Health. 2009 May;9(1):13. https://doi.org/10.1186/1472-6831-9-13

17. Paula JS, Zina LG, Jamieson L, Mialhe FL. The effect of caries increment on oral health-related quality of life among adolescents in Brazil: a 3-year longitudinal study. Braz Oral Res. 2020;34:e107. https://doi.org/10.1590/1807-3107bor-2020.vol34.0107

18. Pahel BT, Rozier RG, Slade GD. Parental perceptions of children's oral health: the Early Childhood Oral Health Impact Scale (ECOHIS). Health Qual Life Outcomes. 2007 Jan;5(1):6. https://doi.org/10.1186/1477-7525-5-6

19. Frencken JE, Amorim RG, Faber J, Leal SC. The Caries Assessment Spectrum Index and Treatment (CAST): rational and development. Int Dent J. 2011 Jun;61(3):117-23. https://doi.org/10.1111/j.1875-595X.2011.00022.x

20. Scarpelli AC, Oliveira BH, Tesch FC, Leão AT, Pordeus IA, Paiva SM. Psychometric properties of the Brazilian version of the Early Childhood Oral Health Impact Scale (B-ECOHIS). BMC Oral Health. 2011 Jun;11(1):19. https://doi.org/10.1186/1472-6831-11-19

21. World Health Organization. Calibration of examiners for oral health epidemiological surveys. Geneva: ORH/EPID; 1993.

22. Almeida RF, Leal SC, Medonca JG, Hilgert LA, Ribeiro AP. Oral health and school performance in a group of schoolchildren from the Federal District, Brazil. J Public Health Dent. 2018 Sep;78(4):306-12. https://doi.org/10.1111/iphd.12273

23. Foster Page LA, Boyd D, Thomson WM. Do we need more than one Child Perceptions Questionnaire for children and adolescents? BMC Oral Health. 2013 Jun;13(1):26. https://doi.org/10.1186/1472-6831-13-26 
- Impact of dental treatment on the oral health-related quality of life of Brazilian schoolchildren

24. Paula JS, Tôrres LH, Ambrosano GM, Mialhe FL. Association between oral health-related quality of life and atraumatic restorative treatment in school children: an exploratory study. Indian J Dent Res. 2012 Nov-Dec;23(6):738-41. https://doi.org/10.4103/0970-9290.111249

25. Cohen J. The earth is round ( $p$ <. 05). Am Psychol. 1994;49(12):997-1003. https://doi.org/10.1037/0003-066X.49.12.997.

26. Husted JA, Cook RJ, Farewell VT, Gladman DD. Methods for assessing responsiveness: a critical review and recommendations. J Clin Epidemiol. 2000 May;53(5):459-68. https://doi.org/10.1016/S0895-4356(99)00206-1

27. Casamassimo PS, Thikkurissy S, Edelstein BL, Maiorini E. Beyond the dmft: the human and economic cost of early childhood caries. J Am Dent Assoc. 2009 Jun;140(6):650-7. https://doi.org/10.14219/jada.archive.2009.0250

28. Gift HC, Reisine ST, Larach DC. The social impact of dental problems and visits. Am J Public Health. 1992 Dec;82(12):1663-8. https://doi.org/10.2105/AJPH.82.12.1663

29. Machry RV, Tuchtenhagen S, Agostini BA, Teixeira CRS, Piovesan C, Mendes FM, et al. Socioeconomic and psychosocial predictors of dental healthcare use among Brazilian preschool children. BMC Oral Health. 2013 Oct;13(1):60. https://doi.org/10.1186/1472-6831-13-60

30. Vollú AL, Costa MD, Maia LC, Fonseca-Gonçalves A. Evaluation of oral health-related quality of life to assess dental treatment in preschool children with early childhood caries: a preliminary study. J Clin Pediatr Dent. 2018;42(1):37-44. https://doi.org/10.17796/1053-4628-42.1.7

31. Abanto J, Paiva SM, Sheiham A, Tsakos G, Mendes FM, Cordeschi T, et al. Changes in preschool children's OHRQoL after treatment of dental caries: responsiveness of the B-ECOHIS. Int J Paediatr Dent. 2016 Jul;26(4):259-65. https://doi.org/10.1111/ipd.12192

32. Paula JS, Sarracini KL, Meneghim MC, Pereira AC, Ortega EM, Martins NS, et al. Longitudinal evaluation of the impact of dental caries treatment on oral health-related quality of life among schoolchildren. Eur J Oral Sci. 2015 Jun;123(3):173-8. https://doi.org/10.1111/eos.12188

33. Mashoto KO, Astrøm AN, Skeie MS, Masalu JR. Changes in the quality of life of Tanzanian school children after treatment interventions using the Child-OIDP. Eur J Oral Sci. 2010 Dec;118(6):626-34. https://doi.org/10.1111/j.1600-0722.2010.00776.x

34. Companhia de Planejamento do Distrito Federal - Codeplan. PDAD - Pesquisa distrital por amostra de domicílios - 2018. Brasília, DF; 2018 [cited 2019 Nov 2]. Available from: http://www.codeplan.df.gov.br/noticias/noticias/item/2137-popula\%C3\%A7\%C3\%A3o-do-par ano\%C3\% A1\%C3 \%A9-de-46527-habitantes.html

35. Martins MT, Sardenberg F, Vale MP, Paiva SM, Pordeus IA. Dental caries and social factors: impact on quality of life in Brazilian children. Braz Oral Res. 2015;29(1):S1806-83242015000100310. https://doi.org/10.1590/1807-3107BOR-2015.vol29.0133

36. Abanto J, Carvalho TS, Mendes FM, Wanderley MT, Bönecker M, Raggio DP. Impact of oral diseases and disorders on oral health-related quality of life of preschool children. Community Dent Oral Epidemiol. 2011 Apr;39(2):105-14. https://doi.org/10.1111/j.1600-0528.2010.00580.x

37. Oliveira LB, Sheiham A, Bönecker M. Exploring the association of dental caries with social factors and nutritional status in Brazilian preschool children. Eur J Oral Sci. 2008 Feb;116(1):37-43. https://doi.org/10.1111/j.1600-0722.2007.00507.x 